\title{
Evolutionary engineered Candida intermedia exhibits improved xylose utilization and robustness to lignocellulose-derived inhibitors and ethanol
}

\author{
Antonio D. Moreno ${ }^{1,2} \cdot$ Antonella Carbone $^{1} \cdot$ Rosita Pavone $^{1} \cdot$ Lisbeth Olsson $^{1} \cdot$ Cecilia Geijer $^{1}$ \\ Received: 3 April 2018 /Revised: 25 October 2018 / Accepted: 17 November 2018 / Published online: 29 November 2018 \\ (C) The Author(s) 2018
}

\begin{abstract}
The development of robust microorganisms that can efficiently ferment both glucose and xylose represents one of the major challenges in achieving a cost-effective lignocellulosic bioethanol production. Candida intermedia is a non-conventional, xyloseutilizing yeast species with a high-capacity xylose transport system. The natural ability of $C$. intermedia to produce ethanol from xylose makes it attractive as a non-GMO alternative for lignocellulosic biomass conversion in biorefineries. We have evaluated the fermentation capacity and the tolerance to lignocellulose-derived inhibitors and the end product, ethanol, of the $C$. intermedia strain CBS 141442 isolated from steam-exploded wheat straw hydrolysate. In a mixed sugar fermentation medium, $C$. intermedia CBS 141442 co-fermented glucose and xylose, although with a preference for glucose over xylose. The strain was clearly more sensitive to inhibitors and ethanol when consuming xylose than glucose. C. intermedia CBS 141442 was also subjected to evolutionary engineering with the aim of increasing its tolerance to inhibitors and ethanol, and thus improving its fermentation capacity under harsh conditions. The resulting evolved population was able to ferment a $50 \%(v / v)$ steam-exploded wheat straw hydrolysate (which was completely inhibitory to the parental strain), improving the sugar consumption and the final ethanol concentration. The evolved population also exhibited a better tolerance to ethanol when growing in a xylose medium supplemented with $35.5 \mathrm{~g} / \mathrm{L}$ ethanol. These results highlight the potential of $C$. intermedia $\mathrm{CBS} 141442$ to become a robust yeast for the conversion of lignocellulose to ethanol.
\end{abstract}

Keywords Non-conventional yeast $\cdot$ Xylose fermentation $\cdot$ Microbial robustness $\cdot$ Lignocellulosic bioethanol

\section{Introduction}

Concerns about global warming and uncertainties in the future energy supply are important driving forces behind the development and implementation of a sustainable bio-based economy. Biorefineries will be used in the future to transform biomass into a wide range of products, including fuels and

Electronic supplementary material The online version of this article (https://doi.org/10.1007/s00253-018-9528-x) contains supplementary material, which is available to authorized users.

Lisbeth Olsson

lisbeth.olsson@chalmers.se

1 Department of Biology and Biological Engineering, Division of Industrial Biotechnology, Chalmers University of Technology, 41296 Gothenburg, Sweden

2 Department of Energy, Biofuels Unit, CIEMAT, Madrid, Spain other energy forms, high value-added chemicals, and other materials, similar to current petroleum-based refineries (Olsson and Saddler 2013). Lignocellulosic biomass is the most abundant form of organic matter in nature (Sánchez and Cardona 2008) and is hence considered the foremost source of raw material for use in biorefineries. Among biomass-derived products, lignocellulosic bioethanol represents an important bulk chemical for the replacement of fossil fuels in the short to medium term. Although significant progress has recently been made towards the commercialization of lignocellulosic bioethanol, several bottlenecks must be resolved to achieve economic and sustainable conversion processes (Balan 2014; Gubicza et al. 2016).

Lignocellulose is composed of three main polymers: cellulose, hemicelluloses, and lignin, linked by covalent and noncovalent bonds to form a complex matrix. Biochemical conversion of lignocellulose includes three major steps: (1) pretreatment, to open up the inherent recalcitrant structure, (2) enzymatic hydrolysis, for the saccharification of carbohydrate 
polymers, and (3) microbial fermentation, to transform the hydrolyzed sugars into useful products such as ethanol. The pretreatment step is usually performed under harsh conditions (such as high temperatures and pressures and/or low/high $\mathrm{pH}$ ), which leads to extensive biomass degradation, generating various lignocellulose-derived compounds such as aliphatic acids, furan derivatives, and several phenolic compounds (Alvira et al. 2010). These compounds inhibit hydrolytic enzymes as well as fermentative microorganisms, thereby decreasing both the overall conversion yields and the microbial fermentation capacity (Taherzadeh and Karimi 2011; Jönsson et al. 2013). For instance, the furan derivatives furfural and 5hydroxymethylfurfural have a direct impact on fermentative cells by inhibiting glycolytic and/or fermentative enzymes, thus reducing biomass formation and ethanol yields (Horváth et al. 2003). Furthermore, inhibitory compounds have been shown to exert a synergistic action on fermentative microorganisms, which can inhibit their growth, even at low concentrations (Oliva et al. 2004; Alvira et al. 2013). Another relevant stress factor affecting fermentation is the end product, ethanol, as it impedes cell growth and reduces viability, thus limiting the fermentation productivity and final conversion yields (Stanley et al. 2010).

Most fermentative microorganisms are capable of removing and/or tolerating inhibitory compounds (Ask et al. 2013; Lindberg et al. 2013; Adeboye et al. 2017). This natural robustness can be improved by subjecting the microorganism to evolutionary engineering (Sauer 2001), by exposing the cells to sublethal inhibitory concentrations of a specific stressor to promote enrichment of cells with a selective advantage at the expense of the initially dominant cells. The advantages of using evolutionary engineering to increase microbial robustness are (1) no detailed knowledge of the microorganism is necessary, (2) resistance to multiple stress factors may be promoted at the same time, and (3) no external genetic modifications are introduced, thus preserving the non-GMO classification of the microorganism (Sauer 2001; Koppram et al. 2012).

Saccharomyces cerevisiae is currently the most commonly used fermentative microorganism in the starch-based bioethanol industry due to its superior fermentation capacity of hexose sugars, particularly glucose. Moreover, in comparison with most other microorganisms characterized to date, $S$. cerevisiae exhibits a high tolerance to ethanol as well as lignocellulose-derived inhibitors (Piskur et al. 2006; Stanley et al. 2010; Parawira and Tekere 2011; Koppram et al. 2014). However, the major disadvantage of using S. cerevisiae strains to produce bioethanol from lignocellulosic materials is its inability to ferment pentoses such as D-xylose and L-arabinose (Sun and Cheng 2002; Hahn-Hägerdal et al. 2007). As xylose is the second most prevalent sugar monomer after glucose in lignocellulosic hydrolysates, and hence a highly important substrate, extensive research efforts have been made to introduce heterologous genes for xylose metabolism into
S. cerevisiae (Moyses et al. 2016). These metabolic engineering approaches are often followed by evolutionary engineering and/or inverse metabolic engineering to optimize the $\mathrm{xy}$ lose uptake and fermentation capacity. Although considerable progress has been achieved, engineered strains still suffer from inefficient xylose uptake and sequential fermentation of glucose and xylose (Subtil and Boles 2012). Furthermore, inefficient cofactor recycling during the catalysis of the NADPH-preferring xylose reductase and the $\mathrm{NAD}^{+}$-dependent xylitol dehydrogenase enzymes results in the accumulation of xylitol as a by-product, thus reducing the overall yield of ethanol on xylose (Jeffries and Jin 2004). Native xylosefermenting yeasts, including species of the genera Scheffersomyces (Scheffersomyces stipitis and Scheffersomyces shehatae), Spathaspora (Spathaspora passalidarum), Pachysolen (Pachysolen tannophilus), and Candida (Candida tropicalis and Candida tenuis), can be considered as alternatives to these genetically modified S. cerevisiae strains (Sánchez et al. 2002; Gárdonyi et al. 2003; Su et al. 2015).

The yeast Candida intermedia is also an interesting pentose-fermenting microorganism since it exhibits similar specific growth rates in glucose and xylose (Gárdonyi et al. 2003), expresses potent xylose transporters (Leandro et al. 2006), and has been shown to ferment glucose and xylose at high concentrations (Saito et al. 2017). Furthermore, it harbors multiple isoforms of xylose reductases, one of which has dual cofactor specificity, which may contribute to a better redox balance (Nidetzky et al. 2003). A new strain of C. intermedia, CBS 141442, was recently isolated in our lab from the liquid fraction of a steam-pretreated wheat straw hydrolysate (Moreno et al. 2017). The aim of this study was to determine the capacity of CBS 141442 to ferment glucose and xylose and its tolerance to lignocellulose-derived inhibitors and ethanol. Moreover, the strain was subjected to evolutionary engineering to improve its robustness and its ability to ferment xylose under limiting conditions.

\section{Materials and methods}

\section{Lignocellulosic hydrolysate}

The liquid fraction (hydrolysate) collected from an acidcatalyzed steam-exploded wheat straw was used as a source of lignocellulose-derived inhibitors. The hydrolysate was recovered by vacuum filtration of the whole pretreated slurry, which was kindly provided by SEKAB E Technology (Örnsköldsvik, Sweden). Selected pretreatment conditions were similar to those reported as "mild pretreatment" by Nielsen et al. (2016). The chemical composition of the collected hydrolysate was analyzed as described below and is given in Table 1. 
Table 1 Chemical composition of the lignocellulosic hydrolysate obtained after acid-catalyzed steam explosion pretreatment of wheat straw

\begin{tabular}{ll}
\hline Compound & Concentration $(\mathrm{g} / \mathrm{L})$ \\
\hline Sugars & \\
Glucose & $6.0 \pm 0.5$ \\
Xylose & $34.1 \pm 1.0$ \\
Arabinose & $5.5 \pm 0.3$ \\
Galactose & $1.9 \pm 0.2$ \\
Inhibitory compounds & \\
Acetic acid & $5.7 \pm 0.5$ \\
Formic acid & $0.5 \pm 0.2$ \\
Furfural & $3.9 \pm 0.4$ \\
5-HMF & $0.8 \pm 0.1$ \\
pH & 3.1 \\
5-HMF 5-hydroxymethylfurfural & \\
\hline
\end{tabular}

The hydrolysate was divided into two batches. One batch was supplemented with glucose, up to $20 \mathrm{~g} / \mathrm{L}$, and the $\mathrm{pH}$ adjusted to 5, and was used for evolutionary engineering and cell pre-adaptation during inoculum preparation. The second batch was first diluted with water to a final concentration of $30-50 \%(v / v)$, supplemented with $\left(\mathrm{NH}_{4}\right)_{2} \mathrm{PO}_{4}(0.5 \mathrm{~g} / \mathrm{L})$, glucose (up to $10 \mathrm{~g} / \mathrm{L}$ ) and xylose (up to $20-30 \mathrm{~g} / \mathrm{L}$ ), and the $\mathrm{pH}$ adjusted to 5.5, and used in fermentation assays. Both batches were stored at $4{ }^{\circ} \mathrm{C}$ prior to use.

\section{Microorganisms and medium composition}

The in-house isolated yeast $C$. intermedia CBS 141442 (haploid strain) was used as the parental strain in the present work (Moreno et al. 2017). This strain was subjected to evolutionary engineering as described below, resulting in two evolved populations: $C$. intermedia $\mathrm{EVO} 1$ and $C$. intermedia $\mathrm{EVO} 2$. Cells were stored at $-80{ }^{\circ} \mathrm{C}$ in $20 \%(v / v)$ glycerol prior to inoculation.

C. intermedia cells were grown in liquid minimal mineral medium (MM) $\left(7.5 \mathrm{~g} / \mathrm{L}\left(\mathrm{NH}_{4}\right)_{2} \mathrm{SO}_{4}, 3.5 \mathrm{~g} / \mathrm{L} \mathrm{KH}_{2} \mathrm{PO}_{4}, 0.75 \mathrm{~g} /\right.$ $\mathrm{L} \mathrm{MgSO}_{4} \cdot 7 \mathrm{H}_{2} \mathrm{O}, 2 \mathrm{~mL} / \mathrm{L}$ trace metal solution, and $1 \mathrm{~mL} / \mathrm{L}$ vitamin solution) (Verduyn et al. 1990), or rich medium (YP) (10 g/L yeast extract and $20 \mathrm{~g} / \mathrm{L}$ peptone), both were supplemented with $20 \mathrm{~g} / \mathrm{L}$ glucose (MMD, YPD), $20 \mathrm{~g} / \mathrm{L}$ xylose (MMX, YPX), or 10 or $40 \mathrm{~g} / \mathrm{L}$ glucose and $20 \mathrm{~g} / \mathrm{L}$ xylose (MM10G20X; MM40G20X).

\section{Random mutagenesis and sequential evolutionary engineering}

C. intermedia 141442 was subjected to sequential evolutionary engineering in the presence of lignocellulose-derived inhibitors and ethanol (Fig. 1). Prior to evolutionary engineering, $C$. intermedia cells were randomly mutagenized using UV light. Cells from MM cultures $\left(100 \mu \mathrm{L}, \mathrm{OD}_{600}=1\right)$ were spread on $\mathrm{MM}$ agar plates and placed upside-down with lids removed on a UVtransilluminator (UVP, Cambridge, UK). High-intensity irradiation capacity at a wavelength of $302 \mathrm{~nm}$ (UVB), which is known to induce DNA mutations (Armstrong and Kunz 1990), was used for 20,40, and $60 \mathrm{~s}$ according to preliminary data showing low, mid, and mid-high $\%$ kill. Non-treated and UV-treated cells were then pooled together to create a start population with a large genetic variability, inoculated into a $100-\mathrm{mL}$ flask containing $50 \mathrm{~mL}$ selective medium at $5 \%(v /$ v) hydrolysate concentration (YP supplemented with $20 \mathrm{~g} / \mathrm{L}$ xylose and $5 \%(v / v)$ hydrolysate), and incubated in an orbital shaker at $30^{\circ} \mathrm{C}$ and $100-150 \mathrm{rpm}$.

The first stage of the evolutionary engineering process was performed at increased concentrations of lignocellulose-derived inhibitors, and cells were grown in repetitive batch cultures with selective medium at 5-15\% $(v / v)$ hydrolysate concentration. Briefly, the concentration of hydrolysate was increased from 5 to $7.5 \%, 10 \%, 12.5 \%$, and $15 \%(v / v)$, after observing an increase in specific growth rate in the corresponding selective medium. Each subculturing round started with an initial $\mathrm{OD}_{600 \mathrm{~nm}}$ value of 0.05 . The cells capable of growing in selective medium at $15 \%(v / v)$ were then subjected to a second round of UV mutagenesis, following the same procedure as described above. The pool of UV-treated cells was then inoculated into $50 \mathrm{~mL}$ selective medium at $20 \%(v / v)$ hydrolysate concentration, continuing the evolution rounds until cells were capable of growing in selective medium at 30\% $(v / v)$ hydrolysate concentration (a 2-fold increase in the hydrolysate concentration tolerated by the parental strain). The intermediate population $C$. intermedia EVO 1 was obtained from this first stage of the evolution process.

A similar subculturing procedure was used in the second stage of the process to further evolve C. intermedia EVO 1 using ethanol as the selective pressure. Repetitive batch cultures were performed in YPX medium supplemented with $31.6 \mathrm{~g} / \mathrm{L}$ ethanol. Each new subculturing round started with an initial $\mathrm{OD}_{600 \mathrm{~nm}}$ value of 0.1 , since a higher initial biomass content was needed to overcome growth inhibition. To avoid ethanol oxidation by $C$. intermedia cells as evolutionary strategy, shaking was maintained at $100 \mathrm{rpm}$ during the whole evolution process. Cells were grown under these conditions until an increase in the specific growth rate was observed (about 12 rounds). This second stage of evolutionary engineering resulted in the final evolved population C. intermedia EVO 2.

To monitor the cultures for contaminating wild yeasts, cells were sampled both during the evolutionary engineering experiments and from the end populations EVO 1 and EVO 2. DNA was extracted and the ITS region was amplified with PCR 
Fig. 1 Schematic representation of the evolutionary engineering of C. intermedia CBS 141442. The evolved population EVO 1 was obtained after 2 cycles of random mutagenesis with UV light and short-term adaptation in the presence of lignocellulosederived inhibitors $(5-30 \%(v / v)$ wheat straw hydrolysate). This intermediate population was subsequently subjected to shortterm adaptation in the presence of $31.6 \mathrm{~g} / \mathrm{L}$ ethanol, resulting in the final evolved population EVO 2

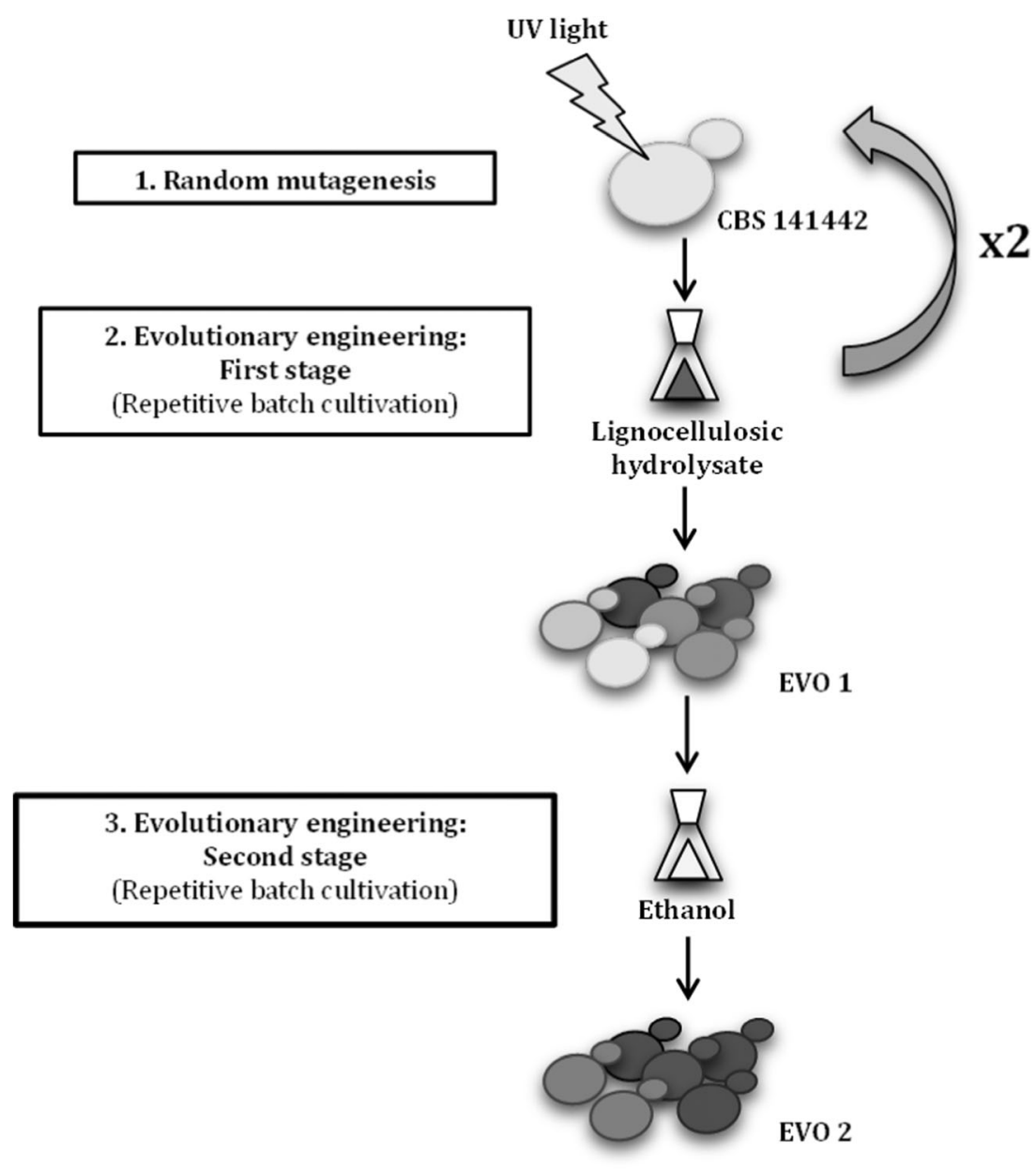

using the ITS1 and ITS4 primers (White et al. 1990), and the species of origin was determined by sequencing and/or estimating the size of the PCR product.

Whenever the evolved populations EVO 1 and EVO 2 were used to inoculate starter cultures for fermentation tests, cells were diluted about 1000 times to ensure that they grew for 10-11 generations in non-selective medium before harvest and reinoculated in the fermentation medium. This way, stable genetic changes rather than short-term adaptation mechanisms are the expected causes for the improved tolerance of the evolved populations.

\section{Fermentation of synthetic medium and lignocellulosic hydrolysate}

The fermentation performance of $C$. intermedia was evaluated in the presence and absence of lignocellulose-derived inhibitors. In the absence of inhibitory compounds, MM10G20X and MM40G20X were used as fermentation media, while $30 \%, 40 \%$, or $50 \%(v / v)$ hydrolysates were used to evaluate the inhibitory tolerance. In all cases, fermentation was performed at $30{ }^{\circ} \mathrm{C}$ and $150 \mathrm{rpm}$ in $100-\mathrm{mL}$ shake flasks, with $30 \mathrm{~mL}$ of the appropriate fermentation medium, using an inoculum concentration of $3 \mathrm{~g} / \mathrm{L}$ cell dry weight. Fermentation assays were carried out in duplicate or triplicate under reduced oxygen concentration conditions by employing an airlock system that allows $\mathrm{CO}_{2}$ outflow and prevents $\mathrm{O}_{2}$ inflow. Samples were withdrawn periodically for analytical purposes. The results are presented as the average values and standard deviations.

Prior to inoculation, precultivated cells were obtained by incubation for $24 \mathrm{~h}$ at $30{ }^{\circ} \mathrm{C}$ and $150 \mathrm{rpm}$ in 500-mL baffled flasks containing $100 \mathrm{~mL}$ MM10G20X. Furthermore, when $30-50 \%(v / v)$ hydrolysate was used as fermentation medium, a pre-adaptation phase was included during preculture, since this has been shown to be crucial for xylose fermentation (Nielsen et al. 2015). Thus, after 16-18 h of cell culture $\left(\mathrm{OD}_{600 \mathrm{~nm}}=2-3\right)$, lignocellulosic hydrolysate (that supplemented with $20 \mathrm{~g} / \mathrm{L}$ glucose and a $\mathrm{pH}$ of 5) was added to a final concentration of $15 \%(v / v)$. The cultures were then further incubated under the same conditions $\left(30{ }^{\circ} \mathrm{C}\right.$ and $150 \mathrm{rpm}$ ) for $8 \mathrm{~h}$. Active cells were harvested by centrifugation at $5000 \mathrm{~g}$ at room temperature for $5 \mathrm{~min}$. The supernatant was discarded, and the cell pellet was washed once with sterile water. The cell pellet was then weighed to obtain the desired inoculum size. 


\section{Cell growth in the presence of ethanol}

The tolerance of $C$. intermedia to ethanol was evaluated in YPD and YPX media supplemented with 0-39.5 g/L ethanol. For preculture, cells growing in the exponential phase, in YPD or YPX, were transferred to $50 \mathrm{~mL}$ of the corresponding test medium to a final $\mathrm{OD}_{600 \mathrm{~nm}}$ of 0.1 . The cultures were then incubated in an orbital shaker at $30^{\circ} \mathrm{C}$ at $150 \mathrm{rpm}$ for $48 \mathrm{~h}$. Samples were withdrawn periodically to monitor cell growth in terms of $\mathrm{OD}_{600 \mathrm{~nm}}$. To evaluate the effect of ethanol on yeast growth, kinetic parameters related to ethanol inhibition were estimated using Luong's eq. (1) (Luong 1985):

$\frac{\mu_{e}}{\mu_{0}}=1-\left(\frac{P}{P_{\max }}\right)^{\alpha}$

where $\mu_{\mathrm{e}}$ and $\mu_{0}$ are the maximum specific growth rates $\left(\mathrm{h}^{-1}\right)$ in the presence and absence of ethanol, respectively; $P$ is the ethanol concentration $(\mathrm{g} / \mathrm{L}) ; P_{\max }$ is the critical ethanol concentration $(\mathrm{g} / \mathrm{L})$ above which there is no growth; and $\alpha$ is the ethanol tolerance index, which describes the type of inhibition ( $\alpha=1$ linear relationship; $\alpha<1$ hyperbolic relationship; $\alpha>1$ parabolic relationship). Values of $P_{\max }$ and $\alpha$ were obtained by plotting $\operatorname{Ln}\left(1-\mu_{e} / \mu_{0}\right)$ versus $\operatorname{Ln}(P)$.

\section{Analytical methods}

The concentrations of glucose, xylose, xylitol, glycerol, acetate, ethanol, 5-hydroxymethylfurfural (5-HMF), and furfural were determined using high-performance liquid chromatography (Dionex-Thermo Fisher Scientific, Sunnyvale, CA, USA), with a Rezex ROA-organic acid $\mathrm{H}^{+}$column (Phenomenex, Torrance, CA, USA). The operating temperature was $80^{\circ} \mathrm{C}$ and the flow rate of the mobile phase $(5 \mathrm{mM}$ $\mathrm{H}_{2} \mathrm{SO}_{4}$ ) was $0.8 \mathrm{~mL} / \mathrm{min}$. Compounds were identified using a refractive index detector at $35{ }^{\circ} \mathrm{C}$ (Dionex RI-101) and a UV detector at $210 \mathrm{~nm}$ (UltiMate 3000 VWD), both from Dionex-Thermo Fisher Scientific (Sunnyvale, CA, USA).

Cell growth was monitored spectrophotometrically (Genesys 20 Spectrophotometer; Thermo Fisher Scientific, Waltham, MA, USA) by measuring the absorbance at $600 \mathrm{~nm}$. Maximum specific growth rates $\left(\mu_{\max }\left(\mathrm{h}^{-1}\right)\right)$ were estimated when cells were growing in the exponential phase using linear regression analysis, by plotting $\operatorname{Ln}\left(O D_{600 n m}\right)$ versus $t(\mathrm{~h})$.

The xylose consumed $\left(C_{X}(\%)\right)$ Eq. (2), xylose consumption rates $\left(Q_{X}(\mathrm{~g} / \mathrm{L} \mathrm{h})\right)$ Eq. (3) and ethanol yield $(Y E(\mathrm{~g} / \mathrm{g}))$ Eq. (4) were estimated as follows:

$C_{x}(\%)=\frac{\left(\text { xylose }_{i}-\text { xylose }_{f}\right) \times 100}{x \operatorname{lose}_{i}}$
$Q_{x}(g / L h)=\frac{\left(x y \operatorname{lose}_{i}-x y \operatorname{lose}_{f}\right)}{\left(t_{f}-t_{i}\right)}$

$Y_{E}(g / g)=\frac{\text { ethanol }_{f}}{\left(\text { sugars }_{i}-\text { sugars }_{f}\right)}$

where the subscripts ${ }_{\mathrm{i}}$ and ${ }_{\mathrm{f}}$ denote the initial and final concentrations in $\mathrm{g} / \mathrm{L}$, respectively.

\section{Results}

\section{Fermentation performance of $C$. intermedia CBS 141442 in the absence of inhibitory compounds}

Efficient conversion of both glucose and xylose is required for cost-effective lignocellulosic bioethanol production. To determine the suitability of $C$. intermedia CBS 141442 as a cell factory for this purpose, its fermentative performance was evaluated in the absence of inhibitory compounds. C. intermedia is a Crabtree-negative yeast, and thus, the fermentation tests were conducted under low oxygen conditions, as this is a prerequisite for fermentation in these yeasts (Rizzi et al. 1989). We also evaluated the fermentation capacity in different initial glucose concentrations, as the glucose content of lignocellulosic hydrolysates is dependent on whether cellulose is hydrolyzed and collected with the corresponding solubilized hemicelluloses or not (Olsson et al. 2005). Hence, minimal medium supplemented with $20 \mathrm{~g} / \mathrm{L}$ xylose and either 10 or $40 \mathrm{~g} / \mathrm{L}$ glucose (MM10G20X and MM40G20X) was used.

C. intermedia strain CBS 141442 was capable of simultaneous utilization of glucose and xylose during fermentation of MM10G20X and MM40G20X, producing maximum ethanol concentrations of $6.9 \mathrm{~g} / \mathrm{L}$ and $14.4 \mathrm{~g} / \mathrm{L}$ after $72 \mathrm{~h}$, respectively (Fig. 2, Table 2). Based on the amounts of the sugars consumed, these ethanol concentrations correspond to yields of $0.24 \mathrm{~g} / \mathrm{g}$ and $0.33 \mathrm{~g} / \mathrm{g}$, which in turn represent $47 \%$ and $65 \%$ of the theoretical amounts of ethanol that could be produced (considering a theoretical ethanol yield of $0.51 \mathrm{~g} / \mathrm{g}$ from both glucose and xylose). In addition to ethanol, $2.9 \mathrm{~g} / \mathrm{L}$ xylitol was produced when using MM10G20X, while $1.2 \mathrm{~g} / \mathrm{L}$ xylitol and $1 \mathrm{~g} / \mathrm{L}$ glycerol were obtained with MM40G20X (Fig. 2, Table 2). Under these conditions, glucose was always consumed at a higher rate than xylose, showing complete depletion within the first $8 \mathrm{~h}$ (Fig. 2). Moreover, different xylose consumption profiles were observed, depending on the initial glucose concentration. With an initial glucose concentration of $10 \mathrm{~g} / \mathrm{L}$ (MM10G20X), a xylose consumption rate of $0.53 \mathrm{~g} /$ $\mathrm{L} \mathrm{h}$ was reached within the first $24 \mathrm{~h}$, sustained xylose consumption was observed throughout the whole fermentation process, and the initial xylose concentration was reduced by $90 \%$ after $72 \mathrm{~h}$. When the initial glucose concentration was 
Fig. 2 Fermentation of mineral media with an initial xylose concentration of $20 \mathrm{~g} / \mathrm{L}$ and a glucose concentration of a $10 \mathrm{~g} / \mathrm{L}$ (MM10G20X) or b $40 \mathrm{~g} / \mathrm{L}$ (MM40G20X) by the parent C. intermedia strain CBS 141442
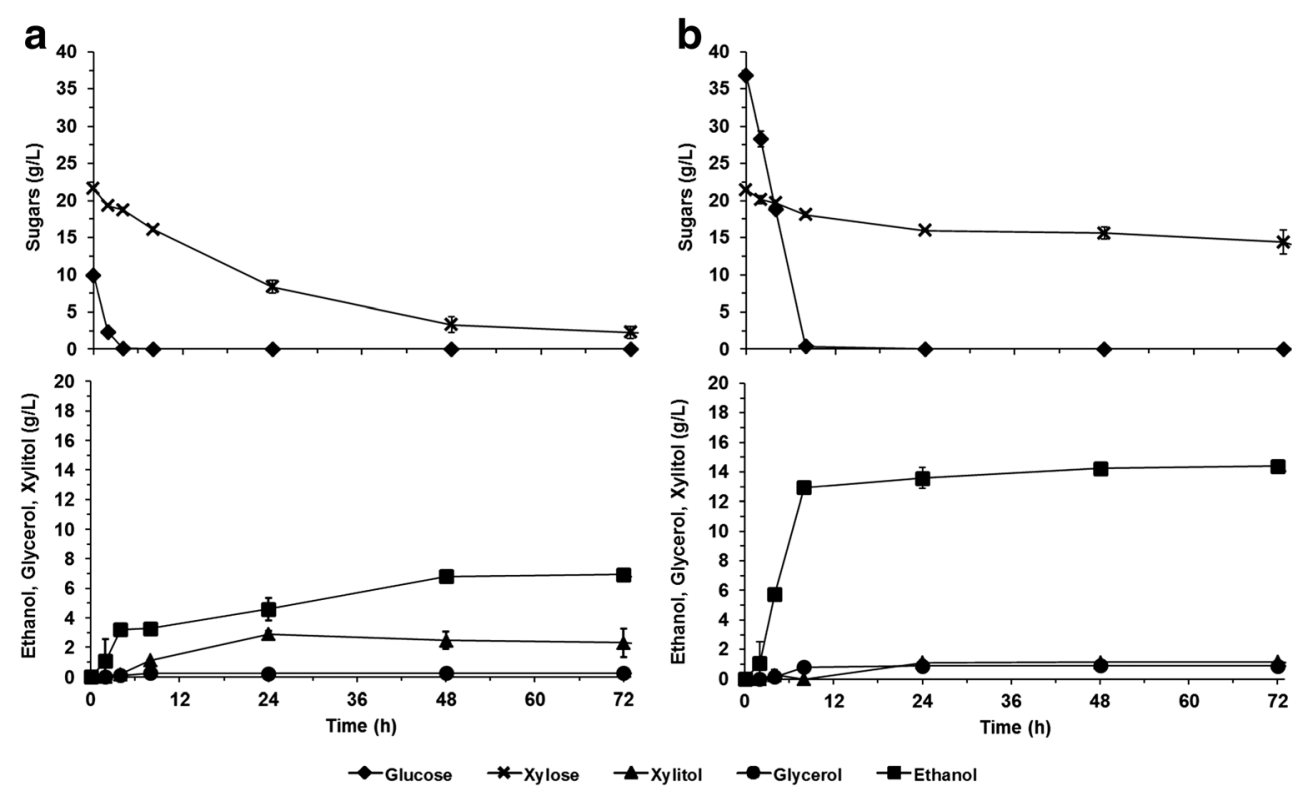

increased to $40 \mathrm{~g} / \mathrm{L}$ (MM40G20X), the initial xylose consumption rate decreased by 2.5 -fold $(0.21 \mathrm{~g} / \mathrm{L} \mathrm{h})$, and almost, no xylose consumption was observed after $24 \mathrm{~h}$ (over $67 \%$ of the initial xylose concentration remained in the fermentation medium after $72 \mathrm{~h}$ ). It is important to note that these experiments were performed in shake flasks without monitoring the oxygen concentration. Thus, a higher initial glucose concentration could lead to increased oxygen consumption, reaching concentrations that are limiting for xylose assimilation (Rizzi et al. 1989). Furthermore, after glucose depletion, the ethanol tolerance of $C$. intermedia CBS 141442 might be not sufficient to allow continued xylose fermentation (Harner et al. 2015). Nevertheless, these results show that $C$. intermedia CBS 141442 can co-ferment glucose and xylose, although it has a preference for glucose.

\section{Effect of lignocellulose-derived inhibitors on growth and fermentation performance of $C$. intermedia CBS 141442}

The fermentation performance of $C$. intermedia CBS 141442 was further investigated in the presence of lignocellulosederived inhibitors by using the liquid fraction collected from steam-exploded wheat straw. Fermentation of wheat straw hydrolysate at $30 \%$ and $40 \%(v / v)$ yielded maximum ethanol concentrations of $7.4 \mathrm{~g} / \mathrm{L}$ and $6.4 \mathrm{~g} / \mathrm{L}$, respectively (Table 2). These ethanol concentrations correspond to conversion yields of $0.27 \mathrm{~g} / \mathrm{g}$ and $0.29 \mathrm{~g} / \mathrm{g}$, based on the consumed sugars. Xylitol was also accumulated during the fermentation process, reaching final concentrations of $3.8 \mathrm{~g} / \mathrm{L}(30 \%(v / v)$ hydrolysate) and $3.3 \mathrm{~g} / \mathrm{L}(40 \%(v / v)$ hydrolysate). Despite the similar conversion yields, a lower final ethanol concentration was observed during the fermentation of $40 \%(v / v)$ hydrolysate due to the reduced xylose consumption (from 55 to $38 \%$ ). A further increase in the hydrolysate concentration from 40 to $50 \%(v / v)$ resulted in complete inhibition of $C$. intermedia CBS 141442, and no sugar consumption or ethanol production was observed within $120 \mathrm{~h}$ (Table 2).

Two of the most important lignocellulose-derived inhibitors, furfural and 5-HMF (10 mM), were sequentially converted by $C$. intermedia in the presence of glucose, whereas the yeast failed to convert these inhibitors in the presence of xylose (Supplementary Fig. S1). Thus, the presence of glucose during the initial stages of the fermentation process benefits the conversion of these biomass-derived inhibitors. After glucose depletion, non-converted inhibitory compounds might have a greater influence on the yeast cells, limiting xylose-to-ethanol conversion, thus explaining the results presented in Table 2 . Therefore, in order to improve xylose conversion and ethanol production by $C$. intermedia, its tolerance to lignocellulose-derived inhibitors must be enhanced.

\section{Effect of ethanol on growth of C. intermedia CBS 141442}

Ethanol is another important inhibitor of cell growth during the conversion of lignocellulose to ethanol. The tolerance of C. intermedia CBS 141442 to different ethanol concentrations was first examined in terms of biomass formation (by measuring $\left.\mathrm{OD}_{600 \mathrm{~nm}}\right)$, in rich medium supplemented with glucose or xylose (YPD/YPX medium was used due to difficulties in measuring $\mathrm{OD}_{600 \mathrm{~nm}}$ in ethanol-supplemented MMD/MMX medium, since the cells agglomerated). Cells subjected to ethanol stress produce less energy, which in turn affects energydemanding processes such as growth (Stanley et al. 2010). No 
differences were observed in terms of biomass formation below an ethanol concentration of $15.8 \mathrm{~g} / \mathrm{L}$, regardless of which sugar was present in the medium (Fig. 3a). However, lower biomass concentrations were observed at ethanol concentrations above $23.7 \mathrm{~g} / \mathrm{L}$ in the presence of glucose (YPD medium) and above $31.6 \mathrm{~g} / \mathrm{L}$ in the presence of xylose (YPX medium).

To determine the extent to which ethanol inhibits cell growth, kinetic parameters for ethanol inhibition of C. intermedia strain CBS 141442 were determined using the kinetic model proposed by Luong (1985). This model establishes the relationship between the specific growth rate $(\mu)$ and the critical ethanol concentration $\left(P_{\max }\right)$, which is described by the ethanol tolerance index $(\alpha)$ (Fig. 3b). When $\alpha>1$ (parabolic inhibition), a slow initial decrease in the specific growth rate is followed by a rapid decrease to zero at sublethal inhibition concentrations. In contrast, when $\alpha<1$ (hyperbolic inhibition), a rapid initial decrease is seen in the specific growth rate followed by a slow decrease to zero as the ethanol concentration is increased. Thus, lower $\alpha$ values indicate greater growth inhibition. In the case of $C$. intermedia CBS 141442 cells growing in glucose, $\alpha$ and $P_{\max }$ were estimated to be 1.3 and $42.7 \mathrm{~g} / \mathrm{L}$, respectively (Fig. 3c). However, cells growing in xylose showed two different inhibition trends, with a turning point at an ethanol concentration of $18.4 \mathrm{~g} / \mathrm{L}$ (Fig. 3d). At this ethanol concentration, $\alpha$ decreased from 2.2 to 0.8 and the critical ethanol concentration $\left(P_{\max }\right)$ was estimated to be $53.2 \mathrm{~g} / \mathrm{L}$. This means that when $C$. intermedia CBS 141442 is growing in the xylose-containing media with ethanol concentrations exceeding $18.4 \mathrm{~g} / \mathrm{L}$, the cells are more severely inhibited per unit ethanol than in the corresponding media containing glucose (Fig. 3a). Apart from the lower tolerance to lignocellulosic-derived compounds in the presence of xylose, the lower tolerance to ethanol when this sugar is present may represent a major drawback for the utilization of C. intermedia in the ethanol industry.

\section{Evolutionary engineering of $C$. intermedia CBS 141442}

In order to improve xylose conversion and ethanol production by $C$. intermedia CBS 141442 , the strain was subjected to evolutionary engineering in two sequential steps to increase its tolerance to lignocellulose-derived compounds (first step) and to ethanol (second step), resulting in the evolved populations EVO 1 and 2 (as described in materials and methods and depicted in Fig. 1).

After evolutionary engineering, the tolerance of the resulting populations to inhibitors was first evaluated by fermentation of 50\% $(v / v)$ hydrolysate. The evolved populations were able to ferment both glucose and xylose with similar fermentation profiles, in contrast to the parental strain (Fig. 4, Table 2, and Supplementary Fig. S2). Fermentation of $50 \%(v / v)$ hydrolysate for $72 \mathrm{~h}$ resulted in ethanol concentrations similar to those obtained during the fermentation of $40 \%(v / v)$ hydrolysate with the parental strain $(6.7 \mathrm{~g} / \mathrm{L}$ and $6.4 \mathrm{~g} / \mathrm{L}$ for EVO 1 and EVO 2, respectively). These ethanol concentrations were further increased to $7.5 \mathrm{~g} / \mathrm{L}$ after $120 \mathrm{~h}$ of fermentation, resulting in a final ethanol conversion yield of $0.26 \mathrm{~g} / \mathrm{g}$ (Table 2). The higher ethanol concentrations were the result of the conversion of higher xylose concentrations by the engineered cells (Table 2). Together with ethanol, $1 \mathrm{~g} / \mathrm{L}$ glycerol and $3.8 \mathrm{~g} / \mathrm{L}$ xylitol were also accumulated (Fig. 4, Table 2, Supplementary Fig. S2). These results suggest that both the

Table 2 Kinetic parameters obtained during the fermentation of mineral media (MM10G20X and MM40G20X) and 30-50\% ( $v / v)$ lignocellulosic hydrolysate with C. intermedia CBS 141442 and the evolved populations EVO 1 and EVO 2

\begin{tabular}{|c|c|c|c|c|c|c|c|}
\hline Strain/population & $\begin{array}{l}\text { Fermentation } \\
\text { medium }\end{array}$ & $\begin{array}{l}\text { Sugars }_{i} \\
(\mathrm{~g} / \mathrm{L})^{\mathrm{a}}\end{array}$ & $\begin{array}{l}\text { Ethanol }{ }_{\max } \\
(\mathrm{g} / \mathrm{L})^{\mathrm{b}}\end{array}$ & $\begin{array}{l}\mathrm{C}_{X} \\
(\mathrm{~g} / \mathrm{L})^{\mathrm{c}}\end{array}$ & $\begin{array}{l}\mathrm{Q}_{\mathrm{X}} \\
(\mathrm{g} / \mathrm{L} \mathrm{h})\end{array}$ & $\begin{array}{l}\text { Xylitol } \\
(\mathrm{g} / \mathrm{L})\end{array}$ & $\begin{array}{l}Y_{E} \\
(g / g)^{d}\end{array}$ \\
\hline C. intermedia CBS 141442 & MM10G20X & $31.6 \pm 0.3(10 \pm 0.1)$ & $6.9 \pm 0.0(72 \mathrm{~h})$ & $19.4 \pm 1.1(89.5 \%)$ & $0.53 \pm 0.04^{\mathrm{e}}$ & $2.9 \pm 0.2$ & 0.24 \\
\hline C. intermedia CBS 141442 & MM40G20X & $58.3 \pm 0.2(36.8 \pm 0.1)$ & $14.4 \pm 0.3(72 \mathrm{~h})$ & $7.1 \pm 1.7(32.9 \%)$ & $0.21 \pm 0.01^{\mathrm{e}}$ & $1.2 \pm 0.0$ & $0.33 \pm 0.01$ \\
\hline C. intermedia CBS 141442 & $30 \%(\mathrm{v} / \mathrm{v}) \mathrm{LH}$ & $41.2 \pm 0.3(10.6 \pm 0.1)$ & $7.4 \pm 1.3(72 \mathrm{~h})$ & $16.6 \pm 4.4(54.6 \%)$ & $0.22 \pm 0.06$ & $3.8 \pm 0.5$ & $0.27 \pm 0.01$ \\
\hline C. intermedia CBS 141442 & $40 \%(\mathrm{v} / \mathrm{v}) \mathrm{LH}$ & $40.2 \pm 0.0(10.7 \pm 0.0)$ & $6.4 \pm 0.4(72 \mathrm{~h})$ & $11.6 \pm 1.6(38.0 \%)$ & $0.14 \pm 0.03$ & $3.3 \pm 0.1$ & $0.29 \pm 0.00$ \\
\hline C. intermedia CBS 141442 & $50 \%(\mathrm{v} / \mathrm{v}) \mathrm{LH}$ & $31.4 \pm 0.1(10.4 \pm 0.0)$ & $0.0 \pm 0.0(120 \mathrm{~h})$ & $0.0 \pm 0.0(0.0 \%)$ & $0.00 \pm 0.00$ & $0.0 \pm 0.0$ & $0.00 \pm 0.00$ \\
\hline C. intermedia $\mathrm{EVO} 1$ & $50 \%(\mathrm{v} / \mathrm{v}) \mathrm{LH}$ & $34.0 \pm 0.2(12.2 \pm 0.0)$ & $7.5 \pm 0.3(120 \mathrm{~h})$ & $16.3 \pm 1.9(75.2 \%)$ & $0.16 \pm 0.02$ & $3.8 \pm 1.1$ & $0.26 \pm 0.03$ \\
\hline C. intermedia $\mathrm{EVO} 2$ & $50 \%(\mathrm{v} / \mathrm{v}) \mathrm{LH}$ & $33.8 \pm 0.1(12.1 \pm 0.0)$ & $7.4 \pm 0.3(120 \mathrm{~h})$ & $16.0 \pm 2.1(73.9 \%)$ & $0.16 \pm 0.03$ & $3.7 \pm 0.5$ & $0.26 \pm 0.01$ \\
\hline
\end{tabular}

Sugarsi total initial glucose and xylose concentration, Ethanolmax maximum ethanol concentration, $C X$ xylose consumed, $Q X$ xylose consumption rate, $Y E$ ethanol yield, $L H$ lignocellulosic hydrolysate

${ }^{a}$ Glucose concentration $(\mathrm{g} / \mathrm{L})$ is given in brackets

${ }^{\mathrm{b}}$ Fermentation time is given in brackets

${ }^{\mathrm{c}}$ Percentage of the xylose consumed is given in brackets

${ }^{\mathrm{d}}$ Ethanol yield was calculated based on consumed glucose and xylose

${ }^{\mathrm{e}} \mathrm{QX}$ calculated based on the values within the first $24 \mathrm{~h}$ of fermentation. The glycerol concentration remained below $1 \mathrm{~g} / \mathrm{L}$ in all fermentations 
Fig. 3 Effect of ethanol on the growth of $C$. intermedia strain CBS 141442 in rich media with glucose (YPD) or xylose (YPX). a Biomass formation in terms of $\mathrm{OD}_{600 \mathrm{~nm}}$ after $48 \mathrm{~h}$ of cultivation. b Inhibition mechanisms according to the ethanol tolerance index $(\alpha)$. c Estimation of $P_{\max }$ and $\alpha$ in the glucose-containing medium. d Estimation of $P_{\max }$ and $\alpha$ in the xylose-containing medium a

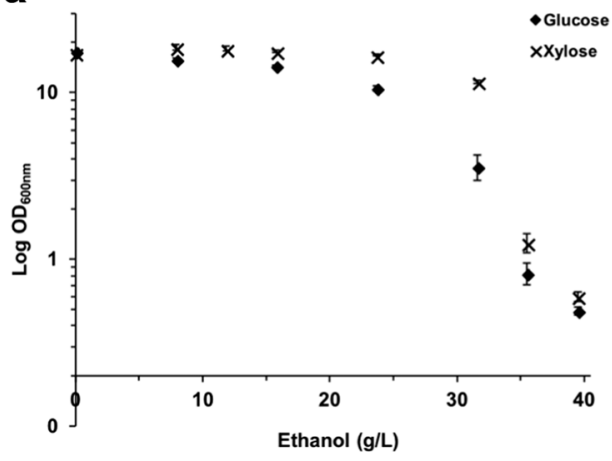

b

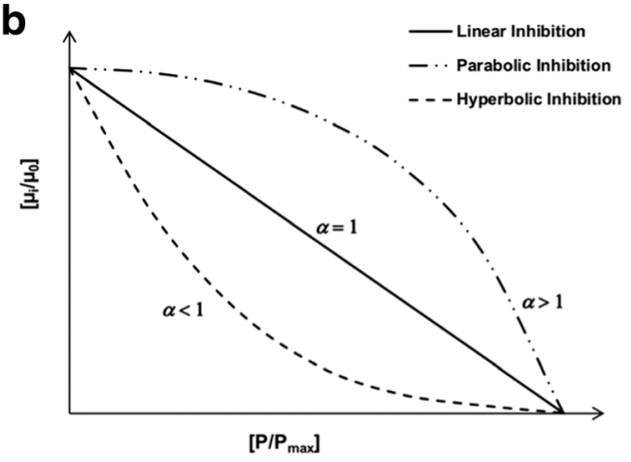

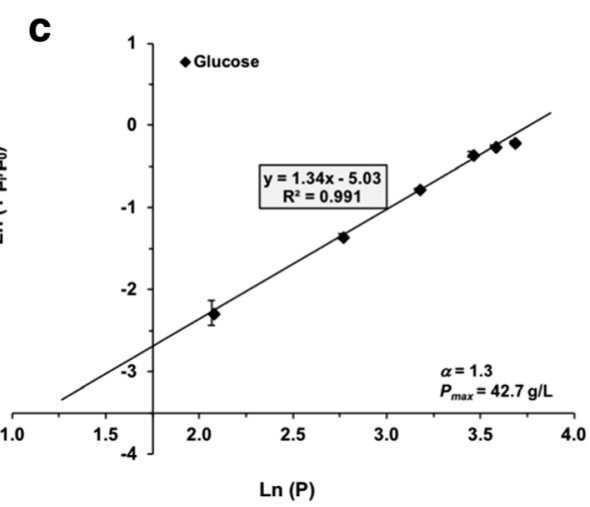

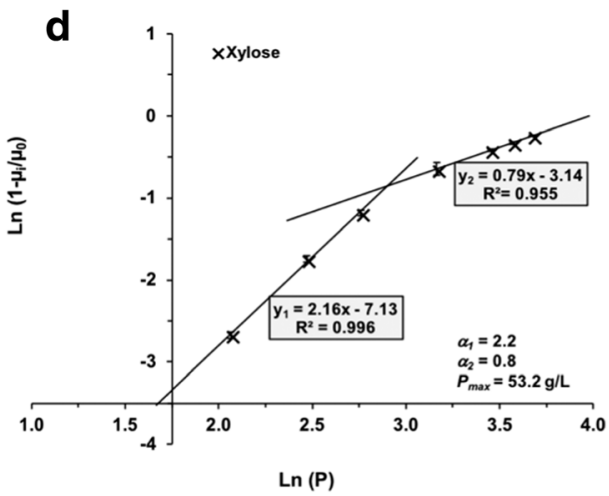

intermediate and the final evolved populations are more tolerant to lignocellulose-derived compounds than the parental strain, and thus better fit for converting xylose in the presence of inhibitors. Furthermore, it is indicative of the genetic stability of evolved populations, since EVO 2 was obtained in absence of lignocellulose-derived inhibitors.

Finally, the tolerance of the evolved populations to ethanol was assessed by cultivation in YPX supplemented with $31.6 \mathrm{~g} / \mathrm{L}, 35.5 \mathrm{~g} / \mathrm{L}$, or $39.5 \mathrm{~g} / \mathrm{L}$ ethanol. These concentrations were found to be highly inhibitory to $C$. intermedia CBS 141442 (Fig. 3). At an ethanol concentration of $31.6 \mathrm{~g} / \mathrm{L}$, populations EVO 1 and EVO 2 showed similar growth patterns and final $\mathrm{OD}_{600 \mathrm{~nm}}$ values to those observed for the parental strain (Fig. 5). However, an increase in the ethanol concentration from 31.6 to $35.5 \mathrm{~g} / \mathrm{L}$ resulted in severe growth inhibition of the parental strain and the evolved population EVO 1, reaching a final $\mathrm{OD}_{600 \mathrm{~nm}}$ of about 1 , and showing no additional growth after $24 \mathrm{~h}$ of cultivation, probably due to energy exhaustion (Stanley et al. 2010). The same ethanol concentration $(4.5 \%(v / v))$ had a lower inhibitory effect on the EVO 2 population, which continued to grow for the full $48 \mathrm{~h}$ of measurements, reaching similar values of $\mathrm{OD}_{600 \mathrm{~nm}}$ to those obtained with an ethanol concentration of $4 \%(v / v)$. However, a further increase in the ethanol concentration to $5 \%(v / v)$ had a strong inhibitory effect on EVO 2 cells, reaching a final $\mathrm{OD}_{600 \mathrm{~nm}}$ slightly above 1 (Fig. 5). These results are indicative of the better ethanol tolerance of the final evolved population, and underline the importance of increasing microbial robustness for lignocellulosic bioethanol production.

\section{Discussion}

In order to achieve cost-effective lignocellulosic bioethanol production, the fermenting microorganisms must convert glucose and xylose efficiently into ethanol in a highly challenging
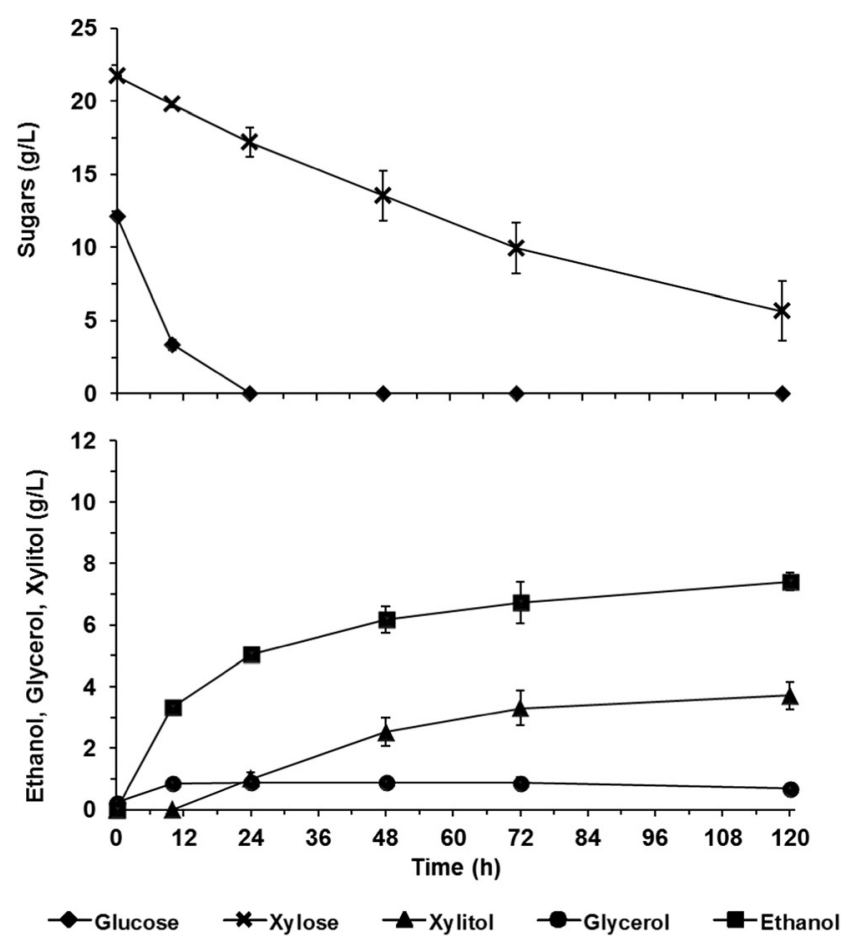

Fig. 4 Fermentation of $50 \%(v / v)$ hydrolysate by the final evolved population $C$. intermedia $\mathrm{EVO} 2$ 
environment. Despite intensive efforts to develop xylosefermenting strains of $S$. cerevisiae, the xylose uptake and the fermentation performance of this yeast have still not reached satisfactory levels (Moyses et al. 2016). The continuous study of native xylose-fermenting yeasts is therefore of the utmost importance to improve our understanding of xylose conversion and to identify key metabolic steps.

In this study, we have characterized the fermentation performance of the in-house isolated $C$. intermedia strain CBS 141442. Simultaneous co-fermentation of glucose and xylose was observed, although xylose was consumed at a lower rate than glucose. Glucose/xylose co-fermentation is a highly desirable trait in simultaneous saccharification and fermentation of lignocellulosic feedstocks, since this process configuration is characterized by high initial xylose concentrations (due to the solubilization of hemicelluloses during the pretreatment step), whereas glucose is continuously released during the fermentation process (Olsson et al. 2005). The preference for glucose over xylose in glucose/xylose mixtures has been observed for most yeast species studied, including S. cerevisiae and natural pentose-fermenting yeasts such as S. stipitis, $S$. shehatae, and also other $C$. intermedia strains (Panchal et al. 1988; Saito et al. 2017). In many cases, this is due to a repression mechanism that impedes the utilization of other carbon sources while glucose is available (Gancedo 1998). Gárdonyi et al. (2003) reported that $C$. intermedia exhibited strong inhibition of xylose utilization in the presence of glucose. Nonetheless, the results presented in the present paper suggest that $C$. intermedia CBS 141442 can assimilate xylose in the presence of glucose, which is a trait worth further exploration.

Moreover, microbial robustness to lignocellulosic inhibitors is of crucial importance for lignocellulosic bioethanol production. C. intermedia CBS 141442 proved to be more sensitive to lignocellulose-derived inhibitors in the xylosefermenting phase than in the glucose-fermenting phase. Moreno et al. (2013) have also reported limited xylose consumption by the xylose-recombinant yeast $S$. cerevisiae strain F12 after glucose depletion. In their study, the low xylose consumption was found to be associated with a decrease in cell viability due to the stress exerted by the inhibitors on the yeast during fermentation. Similarly, $C$. intermedia CBS 141442 might suffer from a loss of cell viability during fermentation of $40 \%$ and $50 \%(v / v)$ hydrolysate due to exposure to high concentrations of lignocellulose-derived compounds. In spite of having inherent mechanisms for tolerating/ converting some of the inhibitory compounds such as furfural and 5-HMF (these compounds can be converted into less inhibitory products by the fermentative microorganisms through oxidation and/or reduction processes), at a certain concentration the synergistic action of the cocktail of inhibitors in a hydrolysate becomes sufficiently high to stop fermentation completely. At the selected fermentation $\mathrm{pH}$ range of 5-5.5, acetic acid $(\mathrm{pKa}=4.75)$ and formic acid $(\mathrm{pKa}=3.75)$ present in the hydrolysate are predominantly in their non-protonated forms and thus expected not to dominate the toxicity effects
Fig. 5 Biomass formation expressed as $\mathrm{OD}_{600 \mathrm{~nm}}$ for the parental $C$. intermedia $\mathrm{CBS}$ 141442 , and the evolved populations EVO 1 and EVO 2 after $48 \mathrm{~h}$ of cultivation in rich medium with xylose containing $31.6 \mathrm{~g} / \mathrm{L}, 35.5 \mathrm{~g} / \mathrm{L}$, or $39.5 \mathrm{~g} / \mathrm{L}$ ethanol
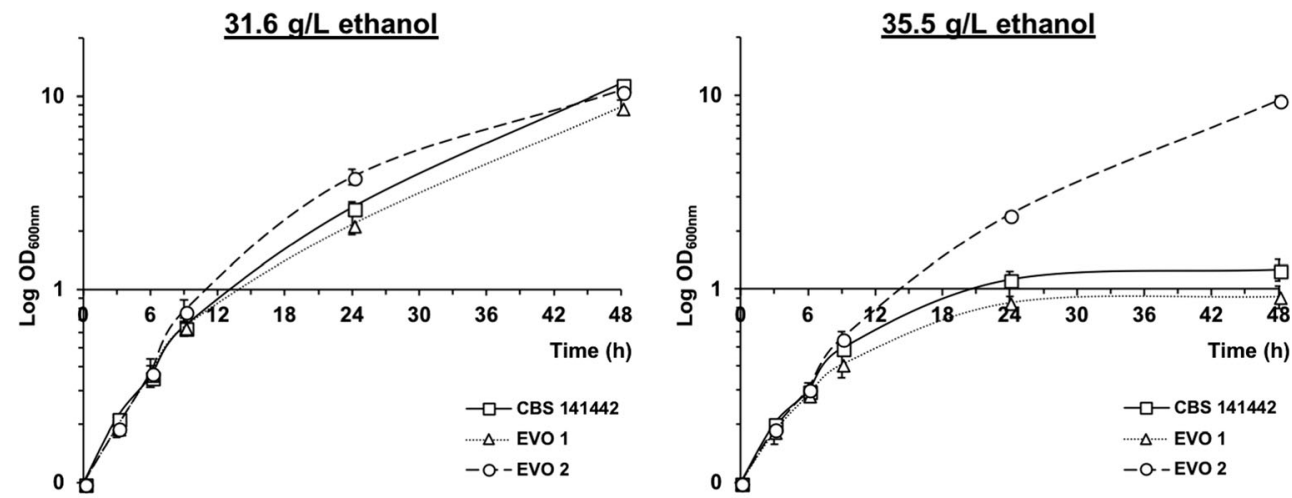

$39.5 \mathrm{~g} / \mathrm{L}$ ethanol

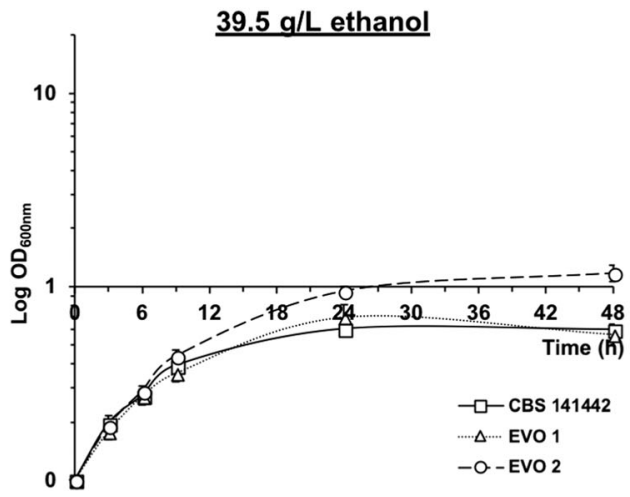


on cells. However, steam-exploded wheat straw hydrolysates usually contain also phenolics and other compounds, not evaluated in this study, that might play significant roles and promote synergistic effects during the inhibition of $C$. intermedia.

Resulting ethanol concentrations must be sufficiently high (above $40 \mathrm{~g} / \mathrm{L}$ ) for the biomass conversion process to be economically viable. Ethanol concentrations of $23.7 \mathrm{~g} / \mathrm{L}$ and $31.6 \mathrm{~g} / \mathrm{L}$ severely affected the growth of $C$. intermedia CBS141442 in media containing glucose and xylose, while concentrations of 43-53 g/L were predicted to be completely inhibitory. Ethanol concentrations in the range of 5-7\% $(v / v)$ have also been reported to be completely inhibitory to species belonging to the Hanseniaspora, Candida, Pichia, Kluyveromyces, Metschnikowia, Torulaspora, and Issatchenkia genera (Ciani et al. 2016). In the case of S. stipitis, which is considered to be one of the best natural xylose-fermenting microbes, the maximum ethanol concentrations at which cells could not grow were estimated to be $33.6 \mathrm{~g} / \mathrm{L}$ (glucose) and $44.7 \mathrm{~g} / \mathrm{L}$ (xylose) (Lee et al. 2000), which are about $20 \%$ lower than those observed in the present study for C. intermedia CBS 141442 (Fig. 3c, d).

According to the results of the growth and fermentation tests performed, we can conclude that $C$. intermedia CBS 141442 has a modest tolerance to lignocellulose-derived compounds and ethanol, especially when utilizing xylose. Therefore, xylose conversion by this yeast strain might be improved by increasing its robustness to these compounds. Evolutionary engineering has proved to be a highly suitable method for enhancing traits in various microorganisms, including non-conventional yeast species for which we lack a detailed knowledge about their physiology as well as tools for targeted genome editing. Moreover, evolutionary engineering makes it possible to target complex polygenic phenotypes, such as tolerance to the cocktail of inhibitors present in lignocellulosic hydrolysates, without prior knowledge about the genes responsible for the trait (Steensels et al. 2014). For example, Nigam (2001) reported overcoming a 65-h lag phase in S. stipitis during fermentation of $60 \%(v / v)$ red oak acid hydrolysate through adaptation of cells on hardwood hemicellulose acid prehydrolysate, and the acetic acid tolerance of a $S$. passalidarum yeast strain was improved by an evolutionary engineering strategy based on UVmutagenesis and subsequent selection by continuous cultivation (Morales et al. 2017). Similarly, the evolutionary engineering strategy employed in the present study resulted in the final evolved population $C$. intermedia EVO 2, which showed improved xylose-to-ethanol conversion in highly challenging environments. Here, the fermentation of 50\% $(v / v)$ hydrolysate, which was completely inhibitory to the parental stain, showed similar final ethanol concentrations and xylose consumption rates to those observed at lower inhibitor concentrations (30$40 \%(v / v)$ hydrolysate), independently of the evolved population used. This result suggests that stable genetic changes are responsible for the corresponding evolved phenotype, since population EVO 2 was obtained in absence of lignocellulosederived inhibitors. Furthermore, the EVO 2 population showed improved ethanol tolerance when growing in xylose medium with an ethanol concentration of $35.5 \mathrm{~g} / \mathrm{L}$, a concentration that caused complete growth inhibition of CBS 141442 after $24 \mathrm{~h}$. Although we cannot completely rule out the possibility that the increased ethanol tolerance is influenced by the rich medium used in the experimental setup, these results highlight the benefit of sequentially applying lignocellulose-derived compounds and ethanol as selective pressures during evolutionary engineering to produce strains with enhanced robustness to these inhibitory compounds. Future studies involve determining the underlying genetic changes responsible for the improved phenotypes, which can yield valuable insights into how the specific traits are established.

The native xylose-fermenting yeast $C$. intermedia has several traits of interest for the conversion of lignocellulosic biomass into bio-based products such as ethanol. These include rapid xylose uptake (Leandro et al. 2006), xylose reductases for better redox balance (Nidetzky et al. 2003), and the simultaneous utilization of both glucose and xylose during fermentation, as shown here. Furthermore, cells with enhanced robustness to lignocellulosic-derived inhibitors and ethanol were obtained by subjecting $C$. intermedia CBS141442 to evolutionary engineering. We believe that the findings of this study may contribute to our understanding of important physiological/genetic traits which will help in the further development and implementation of optimal lignocellulosic biomass conversion processes.

Acknowledgements SEKAB E Technology is gratefully acknowledged for providing the pretreated material. ADM thanks the Spanish Ministry of Economy and Competitiveness and specifically the "Juan de la Cierva" Subprogramme for contract FJCI-2014-22385.

Funding information This project was funded by the Swedish Energy Agency via projects 38779-1 and 38779-2.

\section{Compliance with ethical standards}

Conflicts of interest The authors declare that they have no conflict of interest.

Research involving human participants and/or animals This article does not contain any studies with human participants or animals performed by any of the authors.

Open Access This article is distributed under the terms of the Creative Commons Attribution 4.0 International License (http:// creativecommons.org/licenses/by/4.0/), which permits unrestricted use, distribution, and reproduction in any medium, provided you give appropriate credit to the original author(s) and the source, provide a link to the Creative Commons license, and indicate if changes were made.

Publisher's Note Springer Nature remains neutral with regard to jurisdictional claims in published maps and institutional affiliations. 


\section{References}

Adeboye PT, Bettiga M, Olsson L (2017) ALD5, PAD1, ATF1 and ATF2 facilitate the catabolism of coniferyl aldehyde, ferulic acid and pcoumaric acid in Saccharomyces cerevisiae. Sci Rep 7:42635. https://doi.org/10.1038/srep42635

Alvira P, Tomás-Pejó E, Ballesteros M, Negro MJ (2010) Pretreatment technologies for an efficient bioethanol production process based on enzymatic hydrolysis: a review. Bioresour Technol 101:4851-4861. https://doi.org/10.1016/j.biortech.2009.11.093

Alvira P, Moreno AD, Ibarra D, Sáez F, Ballesteros M (2013) Improving the fermentation performance of Saccharomyces cerevisiae by laccase during ethanol production from steam-exploded wheat straw at high-substrate loadings. Biotechnol Prog 29:74-82. https://doi. org/10.1002/btpr.1666

Armstrong JD, Kunz BA (1990) Site and strand specificity of UVB mutagenesis in the SUP4-o gene of yeast. Proc Natl Acad Sci 87:90059009. https://doi.org/10.1073/pnas.87.22.9005

Ask M, Bettiga M, Mapelli V, Olsson L (2013) The influence of HMF and furfural on redox-balance and energy-state of xylose-utilizing Saccharomyces cerevisiae. Biotechnol Biofuels 6:22. https://doi. org/10.1186/1754-6834-6-22

Balan V (2014) Current challenges in commercially producing biofuels from lignocellulosic biomass. ISRN Biotechnol 2014:463074. https://doi.org/10.1155/2014/463074

Ciani M, Morales P, Comitini F, Tronchoni J, Canonico L, Curiel JA, Oro L, Rodrigues AJ, Gonzalez R (2016) Non-conventional yeast species for lowering ethanol content of wines. Front Microbiol 7:642. https://doi.org/10.3389/fmicb.2016.00642

Gancedo JM (1998) Yeast carbon catabolite repression. Microbiol Mol Biol Rev 62:334-361

Gárdonyi M, Österberg M, Rodrigues C, Spencer-Martins I, HahnHägerdal B (2003) High capacity xylose transport in Candida intermedia PYCC 4715. FEMS Yeast Res 3:45-52. https://doi.org/ 10.1111/j.1567-1364.2003.tb00137.x

Gubicza K, Nieves IU, Sagues WJ, Barta Z, Shanmugam KT, Ingram LO (2016) Techno-economic analysis of ethanol production from sugarcane bagasse using a liquefaction plus simultaneous saccharification and co-fermentation process. Bioresour Technol 208:42-48. https://doi.org/10.1016/j.biortech.2016.01.093

Hahn-Hägerdal B, Karhumaa K, Jeppsson M, Gorwa-Grauslund MF (2007) Metabolic engineering for pentose utilization in Saccharomyces cerevisiae. In: Olsson L (ed) Biofuels. Advances in biochemical engineering/biotechnology, vol 108. Springer, Berlin, Heidelberg

Harner NK, Wen X, Bajwa PK, Austin GD, Ho CY, Habash MB, Trevors JT, Lee H (2015) Genetic improvement of native xylose-fermenting yeasts for ethanol production. J Ind Microbiol Biotechnol 42:1-20. https://doi.org/10.1007/s10295-014-1535-Z

Horváth IS, Franzén CJ, Taherzadeh MJ, Niklasson C, Lidén G (2003) Effects of furfural on the respiratory metabolism of Saccharomyces cerevisiae in glucose-limited chemostats. Appl Environ Microbiol 69(7):4076-4086. https://doi.org/10.1128/AEM.69.7.4076-4086. 2003

Jeffries TW, Jin YS (2004) Metabolic engineering for improved fermentation of pentoses by yeasts. Appl Microbiol Biotechnol 63(5):495509. https://doi.org/10.1007/s00253-003-1450-0

Jönsson LJ, Alriksson B, Nilvebrant N-O (2013) Bioconversion of lignocellulose: inhibitors and detoxification. Biotechnol Biofuels 6:16. https://doi.org/10.1186/1754-6834-6-16

Koppram R, Albers E, Olsson L (2012) Evolutionary engineering strategies to enhance tolerance of xylose utilizing recombinant yeast to inhibitors derived from spruce biomass. Biotechnol Biofuels 5:32. https://doi.org/10.1186/1754-6834-5-32
Koppram R, Tomás-Pejó E, Xiros C, Olsson L (2014) Lignocellulosic ethanol production at high-gravity: challenges and perspectives. Trends Biotechnol 32:46-53. https://doi.org/10.1016/j.tibtech. 2013.10.003

Leandro MJ, Goncalves P, Spencer-Martins I (2006) Two glucose/xylose transporter genes from the yeast Candida intermedia: first molecular characterization of a yeast xylose- $\mathrm{H}^{+}$symporter. Biochem J 395: 543-549. https://doi.org/10.1042/BJ20051465

Lee T-Y, Kim M-D, Kim K-Y, Park K, Ryu Y-W, Seo J-H (2000) A parametric study on ethanol production from xylose by Pichia stipitis. Biotechnol Bioprocess Eng 5:27-31. https://doi.org/10. 1007/bf02932349

Lindberg L, Santos AX, Riezman H, Olsson L, Bettiga M (2013) Lipidomic profiling of Saccharomyces cerevisiae and Zygosaccharomyces bailii reveals critical changes in lipid composition in response to acetic acid stress. PLoS One 8:e73936. https:// doi.org/10.1371/journal.pone.0073936

Luong JH (1985) Kinetics of ethanol inhibition in alcohol fermentation. Biotechnol Bioeng 27:280-285. https://doi.org/10.1002/bit. 260270311

Morales P, Gentina JC, Aroca G, Mussatto SI (2017) Development of an acetic acid tolerant Spathaspora passalidarum strain through evolutionary engineering with resistance to inhibitors compounds of autohydrolysate of Eucalyptus globulus. Ind Crop Prod 106:5-11. https://doi.org/10.1016/j.indcrop.2016.12.023

Moreno AD, Tomás-Pejó E, Ibarra D, Ballesteros M, Olsson L (2013) In situ laccase treatment enhances the fermentability of steamexploded wheat straw in SSCF processes at high dry matter consistencies. Bioresour Technol 143:337-343. https://doi.org/10.1016/j. biortech.2013.06.011

Moreno AD, Tellgren-Roth C, Soler L, Dainat J, Olsson L, Geijer C (2017) Complete genome sequences of the xylose-fermenting Candida intermedia strains CBS 141442 and PYCC 4715. Genome Announc 5:e00138-e00117. https://doi.org/10.1128/ genomeA.00138-17

Moyses DN, Reis VC, de Almeida JR, de Moraes LM, Torres FA (2016) Xylose fermentation by Saccharomyces cerevisiae: challenges and prospects. Int J Mol Sci 17:207. https://doi.org/10.3390/ ijms 17030207

Nidetzky B, Bruggler K, Kratzer R, Mayr P (2003) Multiple forms of xylose reductase in Candida intermedia: comparison of their functional properties using quantitative structure-activity relationships, steady-state kinetic analysis, and pH studies. J Agric Food Chem 51: 7930-7935. https://doi.org/10.1021/jf034426j

Nielsen F, Tomás-Pejó E, Olsson L, Wallberg O (2015) Short-term adaptation during propagation improves the performance of xylosefermenting Saccharomyces cerevisiae in simultaneous saccharification and co-fermentation. Biotechnol Biofuels 8:219. https://doi.org/ 10.1186/s13068-015-0399-4

Nielsen F, Zacchi G, Galbe M, Wallberg O (2016) Prefermentation improves ethanol yield in separate hydrolysis and cofermentation of steam-pretreated wheat straw. Sustain Chem Process 4:10. https:// doi.org/10.1186/s40508-016-0054-9

Nigam JN (2001) Development of xylose-fermenting yeast Pichia stipitis for ethanol production through adaptation on hardwood hemicellulose acid prehydrolysate. J Appl Microbiol 90:208-215. https://doi. org/10.1046/j.1365-2672.2001.01234.x

Oliva JM, Ballesteros I, Negro MJ, Manzanares P, Cabañas A, Ballesteros $M$ (2004) Effect of binary combinations of selected toxic compounds on growth and fermentation of Kluyveromyces marxianus. Biotechnol Prog 20:715-720. https://doi.org/10.1021/bp034317p

Olsson L, Saddler J (2013) Biorefineries, using lignocellulosic feedstocks, will have a key role in the future bioeconomy. Biofuels Bioprod Biorefin 7:475-477. https://doi.org/10.1002/bbb.1443

Olsson L, Jørgensen H, Krogh KBR, Roca CFA (2005) Bioethanol production from lignocellulosic material. In: Dumitriu $\mathrm{S}$ (ed) 
Polysaccharides: structural diversity and functional versatility. Marcel Dekker, New York, pp 957-993

Panchal CJ, Bast L, Russell I, Stewart GG (1988) Repression of xylose utilization by glucose in xylose-fermenting yeasts. Can J Microbiol 34:1316-1320. https://doi.org/10.1139/m88-230

Parawira W, Tekere M (2011) Biotechnological strategies to overcome inhibitors in lignocellulose hydrolysates for ethanol production: review. Crit Rev Biotechnol 31:20-31. https://doi.org/10.3109/ 07388551003757816

Piskur J, Rozpedowska E, Polakova S, Merico A, Compagno C (2006) How did Saccharomyces evolve to become a good brewer? Trends Genet 22:183-186. https://doi.org/10.1016/j.tig.2006.02.002

Rizzi M, Klein C, Schulze C, Bui-Thanh N-A, Dellweg H (1989) Xylose fermentation by yeasts. 5. Use of ATP balances for modeling oxygen-limited growth and fermentation of yeast Pichia stipitis with xylose as carbon source. Biotechnol Bioeng 34:509-514. https://doi. org/10.1016/j.tig.2006.02.002

Saito M, Nagasaki H, Watanabe S, Fujimoto T (2017) Ethanol production from sugars in hydrolysates of cellulosic biomass resources with xylose-fermenting yeast Candida intermedia 4-6-4T2. J Jpn Pet Inst 60:127-136. https://doi.org/10.1627/jpi.60.127

Sánchez OJ, Cardona CA (2008) Trends in biotechnological production of fuel ethanol from different feedstocks. Bioresour Technol 99: 5270-5295. https://doi.org/10.1016/j.biortech.2007.11.013

Sánchez S, Bravo V, Castro E, Moya AJ, Camacho F (2002) The fermentation of mixtures of D-glucose and D-xylose by Candida shehatae, Pichia stipitis or Pachysolen tannophilus to produce ethanol. J Chem Technol Biotechnol 77:641-648. https://doi.org/10.1002/ jctb.622

Sauer U (2001) Evolutionary engineering of industrially important microbial phenotypes. In: Nielsen J, Eggeling L, Dynesen J, Gárdonyi M, Gill RT, de Graaf AA, Hahn-Hägerdal B, Jönsson LJ, Khosla C, Licari R, McDaniel R, McIntyre M, Miiller C, Nielsen J, Cordero Otero RR, Sahm H, Sauer U, Stafford DE, Stephanopoulos G, Wahlbom CE, Yanagimachi KS, van Zyl WH (eds) Metabolic engineering. Springer, Heidelberg, pp 129-169. https://doi.org/10. 1007/3-540-45300-8 7

Stanley D, Bandara A, Fraser S, Chambers PJ, Stanley GA (2010) The ethanol stress response and ethanol tolerance of Saccharomyces cerevisiae. J Appl Microbiol 109:13-24. https://doi.org/10.1111/j. 1365-2672.2009.04657.x

Steensels J, Snoek T, Meersman E, Picca Nicolino M, Voordeckers K, Verstrepen KJ (2014) Improving industrial yeast strains: exploiting natural and artificial diversity. FEMS Microbiol Rev 38(5):947-995. https://doi.org/10.1111/1574-6976.12073

Su YK, Willis LB, Jeffries TW (2015) Effects of aeration on growth, ethanol and polyol accumulation by Spathaspora passalidarum NRRL Y-27907 and Scheffersomyces stipitis NRRL Y-7124. Biotechnol Bioeng 112:457-469. https://doi.org/10.1002/bit.25445

Subtil T, Boles E (2012) Competition between pentoses and glucose during uptake and catabolism in recombinant Saccharomyces cerevisiae. Biotechnol Biofuels 5:14. https://doi.org/10.1186/17546834-5-14

Sun Y, Cheng J (2002) Hydrolysis of lignocellulosic materials for ethanol production: a review. Bioresour Technol 83:1-11. https://doi.org/10. 1016/S0960-8524(01)00212-7

Taherzadeh MJ, Karimi K (2011) Fermentation inhibitors in ethanol processes and different strategies to reduce their effects. In: Pandey A, Larroche C, Ricke SC, Dussap C-G, Gnansounou E (eds) Biofuels. Alternative feedstocks and conversion processes. Academic Press, Amsterdam, pp 287-311

Verduyn C, Postma E, Scheffers WA, van Dijken JP (1990) Physiology of Saccharomyces cerevisiae in anaerobic glucose-limited chemostat cultures. J Gen Microbiol 136:395-403. https://doi.org/10.1099/ 00221287-136-3-395

White TJ, Bruns TD, Lee SB, Taylor (1990) Amplification and direct sequencing of fungal ribosomal RNA genes for phylogenetics. In: Gelfand DH, Sninsky JJ, White TJ (eds) Innis MA. PCR protocols-a guide to methods and applications. Academic Press, London, pp 315-322 